\title{
The Effects of Study Abroad on Spanish Teachers' Self-Efficacy: A Multiple Case Study
}

\section{Christopher Jochum}

Fort Hays State University

\section{Jared R. Rawlings}

University of Utah

\section{Ana María Tejada}

University of Nebraska at Kearney

The relationship between studying abroad and language proficiency is well documented in the foreign language literature (Brecht, Davidson, \& Ginsberg, 1995; Collentine, 2004; Freed, 1995; Jochum, 2014; Schmidt-Rinehart \& Knight, 2004; Segalowitz \& Freed, 2004; Swender, 2003). Yet, very few researchers have studied the effect of study abroad on current or inservice foreign language teachers, who must maintain or improve their language skills throughout their career. Additionally, the concept of self-efficacy, or people's judgments of their abilities to successfully complete a task (Bandura, 1997), is a strong predictor of foreign language achievement (Cubillos, \& Ilvento, 2012, p. 497). As a result, Spanish teachers' feelings of self-efficacy can provide an important measure of their abilities to be effective in the classroom and, perhaps, affect student achievement. There is a need for qualitative research focused on the lived experiences of inservice foreign language teachers while they are immersed in the target culture in order to better understand how those experiences can affect their instructional practices and teacher efficacy.

Therefore, the purpose of this study is to examine current secondary Spanish teachers' feelings of self-efficacy while participating in a summer study abroad program in Costa Rica. The following research question guided this inquiry: How does the study abroad experience affect Spanish teachers' feelings of self-efficacy as it relates to language proficiency and instructional practice?

\section{Teacher self-efficacy}

Bandura (1997) defines self-efficacy as "beliefs in one's capabilities to organize and execute the courses of action required to produce given attainments" (p. 3). For almost four decades, researchers have studied the effects of teacher self-efficacy (Bandura 1977, 1997; Tschannen-Moran \& Johnson, 2011). Studies have shown a relationship between more efficacious teachers and student achievement and motivation (Midgley, Feldlaufer, \& Eccles, 1989; Moore \& Esselman, 1992; Ross, 1992), classroom management (Ashton \& Webb, 1986), instructional planning and organizational skills (Allinder 1994), willingness to spend time with struggling students (Gibson \& Dembo, 1984), enthusiasm for teaching (Allinder, 1994; Guskey, 1984; Hall, Burley, Villeme, \& Brockmeier, 1992), persistence and resiliency in response to setbacks (Tschannen-Moran \& Woolfolk Hoy, 2001) and professional longevity (Burley, Hall, Villeme, \& Brockmeier, 1991). Furthermore, teachers with high levels of self-efficacy have reported reduced stress levels associated with student behavior, teacher- 
administrator relations, and parent-teacher relations (Parkay, Greenwood, Olejnik, \& Proller, 1988). Clearly, efficacious teachers are not only more enthusiastic, work well with all students and stay in the profession longer but can also have a positive impact on student achievement.

Teacher self-efficacy in foreign language research. Researchers have found an association between teacher efficacy and higher student achievement in core content areas such as science (Enochs \& Riggs, 1990), math (Brand \& Wilkins, 2007) and literacy (Tschannen-Moran \& Johnson, 2011). Swanson (2008, 2010, 2012) examined self-efficacy among foreign language teachers and found a relationship between teacher retention and attrition. He also reported (2014) that students of more efficacious teachers are more successful on the AATSP (American Association of Teachers of Spanish and Portuguese) National Spanish Examinations. Therefore, foreign language teachers' sense of self-efficacy is very important as it not only affects their students' achievement but also their job satisfaction and willingness to remain in the profession.

Of particular interest to the present study, researchers have also found an association between foreign language teachers' efficacy and their language proficiency. Chacón (2005) used a mixedmethods design in which she gave English as a Foreign Language (EFL) teachers in Venezuela the Teacher Sense of Efficacy Scale (TSES) (Tschannen-Moran \& Woolfolk Hoy, 2001) along with follow-up interviews where teachers rated the effectiveness of various teaching scenarios or vignettes. Results indicated that there was a correlation between teachers' efficacy and their selfreported levels of English proficiency. Yilmaz (2011) used a modified version of the TSES and also found an association between Turkish EFL teachers' efficacy and their reported levels of language proficiency.

\section{Self-efficacy and study abroad}

There is a wealth of research that reports the benefits of undergraduate students studying abroad and gains in language proficiency (Brecht, Davidson, \& Ginsberg, 1995; Freed, 1995; Schmidt-Rinehart \& Knight, 2004; Segalowitz \& Freed, 2004; Swender, 2003). Furthermore, researchers have also examined the relationship between study abroad and undergraduate students' levels of self-confidence (Allen \& Herron, 2003) and motivation (Allen, 2010).

Cubillos and Ilvento (2012) investigated the relationship between studying abroad and participants' self-efficacy among short and long-term programs. The researchers administered both pre- and post-trip self-efficacy surveys and found significant increases in students' self-efficacy, regardless of the length of stay, related to the four skills of reading, writing, listening and speaking. Furthermore, they reported that "the extent of self-efficacy gains was found to be associated with the extent and type of interaction with members of the host country" (p. 494).

In addition to contributing to more efficacious use of specific language skills, studying abroad can also lead to higher levels of self-efficacy related to intercultural competence, which Covert (2014) defined as "the ability to behave and communicate effectively and appropriately based on one's intercultural knowledge, skills, and attitudes" (p. 163). In her study, Covert examined undergraduate students' perceptions of developing intercultural competence while spending a semester abroad in Chile and found that the study abroad experience can "support students to build their self-efficacy and agency in intercultural interactions" (p. 162). Therefore, after spending time 
abroad, program participants are more likely to exhibit a belief in their ability to achieve intercultural competence.

Studying abroad has also been attributed to building self-efficacy among students whose primary purpose for going abroad is not to improve their language skills. Medina, Hathaway and Pilonieta (2015) conducted a study in which 16 preservice elementary teachers spent eight weeks in Germany studying elementary literacy and math methods (in English with their home professors) and observing local elementary classrooms. While abroad, the participants did not receive specific information about second language acquisition or pedagogy. Nonetheless, the preservice teachers reported higher levels of self-efficacy, as compared to pre-trip measures, associated with teaching English Language Learners (ELLs) such as implementing research-based strategies and infusing appropriate, culturally-relevant materials into their curriculum.

Previous research has indicated that studying abroad can affect participants' self-efficacy related to areas such as intercultural competence and instructional abilities. While the study abroad experience is beneficial to preservice teachers' self-efficacy, there is also a need to better understand how the study abroad experience affects inservice teachers, especially among foreign language teachers who must achieve or maintain minimum levels of proficiency to be effective in the classroom.

\section{Method}

\section{Design}

To investigate how the experience of studying abroad affects inservice Spanish teachers' feelings of self-efficacy, we employed a multiple case study design (Stake, 2006) using multiple data sets to analyze the participants' lived experiences while studying in Costa Rica during the summer of 2014. Moreover, with qualitative data collection, there is a need for the researcher to be in the natural setting in order to observe the targeted phenomenon and the participants' natural reactions in real time (Patton, 2002).

\section{Sampling and Participants}

Four participants were selected based upon criterion sampling, which Patton (2002) describes as "study[ing] all cases that meet some predetermined criterion of importance, a strategy common in quality assurance efforts" (p. 238). Participants for this study met the following criteria: (a) studying abroad in Costa Rica during the summer of 2014; (b) currently enrolled in in a master's program in Spanish education and (c) currently teaching Spanish in a 7-12 setting in the United States. Our most important consideration was to find teachers with an already established rapport with at least one of the researchers so that an element of trust was already present in the researcher-participant relationship. This was accomplished as the first author had worked with all of the participants throughout their graduate program as both their professor and academic advisor. Furthermore, the third author had previously worked with all of the participants as a graduate research assistant.

All of the participants were female, taught Spanish in a 7-12 setting in the United States, and were enrolled in a graduate program at the same institution. In addition, all of the participants identified their ethnicity as Caucasian with their primary, native-language as English. The participants also presented differences that contributed to both the diversity and ultimate analysis of the study. 
Participant profiles include demographic information self-reported during the initial interview with the first and third authors. Pseudonyms have been used to maintain confidentiality and to protect participants' identities.

Participant Profiles. Pamela is 56 year-old Caucasian whose native language is English. Pamela has taught middle and high school Spanish for almost twenty years and although she had spent time in a number of schools, her current assignment is in a small, Midwestern rural district with a student population of approximately 200. The community in which she teaches has less than 1,000 people. Pamela is the only foreign language teacher in her school, where she teaches exploratory Spanish for $7^{\text {th }}$ and $8^{\text {th }}$ grade students and high school Spanish I, II and III. Because her district is so small, most school years she has to combine her Spanish II and III classes into the same instructional period. Pamela feels as though both her administration and students' parents "generally support" foreign language instruction in her school district and community. Due to her state requirements at the time of her initial teacher certification, Pamela was not required to pass a Spanish-proficiency exam to gain licensure. Although Pamela had previously spent short amounts of time traveling in Spanishspeaking countries, she had never participated in a study abroad program. Furthermore, the last time she had spent a significant amount of time in a Spanish-speaking country was 15 years ago when she took her students abroad.

Alissa is a 36-year-old Caucasian whose native language is English. A Spanish teacher with 13 years of experience, she teaches in a large high school located in a metropolitan area on the West Coast of the United States with an approximate enrollment of 2,100 students. Alissa is part of a large World Languages Department and, over her career, has taught all levels of Spanish, including Advanced Placement (AP). She feels as though the parental and administrative support of foreign language education within her school and community is "excellent". Alissa successfully passed licensure exams in two states with minimum oral proficiency requirements of Advanced-Low, per ACTFL guidelines. In addition to extensive travel in Latin America and Spain over the past decade, Alissa also studied abroad for six months as an undergraduate student.

Katie is a 27 year-old, native English-speaking Caucasian who is relatively new to the teaching profession, having taught for only three years. Located in the Northwestern part of the United States, Katie teaches Spanish I and II in a high school with approximately 1,300 students, where she is only one of two Spanish teachers. The community in which she teaches has a population of approximately 80,000. Katie indicated that her administration and parents are very supportive of foreign language education. As an undergraduate student she completed a six-month study abroad experience in a Spanish-speaking country. In addition, she currently teaches in a state that requires a minimum score of Advanced Low on the ACTFL Oral Proficiency Interview for teacher licensure.

Jessica, a 24 year-old Caucasian whose native language is English, was the youngest and least experienced participant, having just completed her second year teaching Spanish at a Midwestern high school with an approximate enrollment of 1,500 (in a community with a population of 30,000). Jessica felt as though her administration and parents were "mostly" supportive of the foreign language program. As part of a World Languages Department with faculty in Spanish and French, she had taught Spanish II and III. However, during the summer of 2014, she attended an Advanced Placement Summer Institute in order to teach AP Spanish the following academic year. Like Pamela, 
Jessica teaches in a state that, at the time of her certification, did not require a content-based licensure exam. Jessica spent six months studying abroad as part of her undergraduate program of study.

\section{Research Setting}

All participants were enrolled in a Masters of Spanish Education program at a mid-sized, Midwestern University, which is regionally accredited through the Higher Learning Commission and the National Council for the Accreditation of Teacher Education (NCATE). The degree program attracts inservice Spanish teachers from across the United States and consists of a mixture of courses related to foreign language pedagogy and Spanish content. While the entire degree can be completed online, many students elect to participate in summer study abroad courses in order to enhance their cultural and linguistic proficiency. This also provides students the additional benefit of meeting and collaborating with their classmates, many of whom they have only known through virtual course interactions.

This study was conducted within a well-established language institute in San José, Costa Rica during the summer of 2014. The institute has provided quality Spanish instruction at all levels (from beginning to advanced-level content courses) for over 25 years and attracts students from all over the world. In the summer of 2013, the first author visited this institute to ensure that it offered a curriculum that was rigorous enough for graduate-level students. Upon arrival, the institute assessed students' Spanish proficiency and placed them in appropriate classes focused on Spanish conversation and advanced grammar. Research participants also had the option of enrolling in free workshops (outside of the instructional day) to enhance their conversational skills speaking in small groups or through taking cooking or dance classes. Jessica, Alissa and Pamela lived with hostfamilies provided by the school; Katie stayed at a nearby apartment.

\section{Data Collection, Procedures and Analysis}

To determine how the study abroad experience affected inservice Spanish teachers' perceptions of self-efficacy related to language proficiency and instructional practice, the following data sets were collected from participants: (a) individual participant interviews; (b) in-country observations of interactions; and (c) participant reflection journals. For the purposes of this study, the individual participant interviews served as the primary data source.

\section{Data Collection}

Seidman (2012) developed a model for phenomenological interviews, which fits the purpose of our study. He suggests a series of three interviews over the time of data collection. Since we were interested in the effect a study abroad program had on the efficacy of inservice foreign language teachers, we felt that the Seidman three-stage phenomenological interview design was a natural fit for our inquiry. The details of each interview appear in the procedures sections below and an interview protocol appears in Appendix A. To support the primary data source (interviews) we also collected data related to our in-country observations and interactions with participants as well as asking them to keep personal reflection journals. 
Table 1. Study Timeline and Procedures.

\begin{tabular}{ll} 
Timeline & Data Source \\
\hline Early May 2014 & Participants were recruited. \\
\hline Late May 2014 & $\begin{array}{l}\text { Pre-trip interviews were conducted (via Skype); } \\
\text { participants began journaling. }\end{array}$ \\
\hline June 2014 & $\begin{array}{l}\text { In-country interviews (face-to-face) and researcher observations were conducted; } \\
\text { participants continued journaling. }\end{array}$ \\
\hline June / July 2014 & $\begin{array}{l}\text { Final in-country interviews (face-to-face) and post-trip interviews (via Skype) } \\
\text { were conducted. Participants concluded journaling; researchers concluded } \\
\text { observations. }\end{array}$ \\
\hline August 2014 & $\begin{array}{l}\text { Researchers began process of coding and determining emergent themes; } \\
\text { participant member checks were conducted. }\end{array}$
\end{tabular}

\section{Procedures}

The Seidman (2012) first interview (focused life history) was modified for this study. Due to geographic constraints, the first interviews were conducted online in May of 2014. The use of computer-mediated communication (CMC), such as Skype, to conduct interviews is supported in the literature (Huffaker \& Calvert, 2005; James \& Busher, 2009; Salmon, 2000). We conducted the second interviews in San José, Costa Rica and third interviews (post-trip) online in June and July of 2014. In-country observations and interactions as well as participant reflection journals also took place throughout the study abroad experience, which consisted of four to six weeks for all participants. Table 1 shows the timeline for data collection.

\section{Data analysis and trustworthiness}

The process of analysis began with the creation of transcripts from all interviews. We communicated regularly through the analysis process and met to discuss emerging codes and themes. Member checks were conducted through the following techniques: (a) during the interviews we regularly paraphrased and asked participants for clarification; (b) transcripts of the interviews were sent to participants for comment; and (c) the interviews included an opportunity for the participant to respond to emerging findings from other individual interviews.

The first and third authors had appropriate rapport with the participants and expertise in the area of study abroad and foreign language teacher professional development while the second author has extensive training and preparation in qualitative research, transcript data analysis as well as teacher education. Furthermore, the third author, as a native Spanish-speaker, provided linguistic support and unique insight into the participants' language skills. The three data sources were triangulated to insure the accuracy of the findings. Finally, although we recognize that these findings may not be generalizable to all inservice foreign language teachers, we are hopeful that some of the experiences of these four teachers may be transferable to other inservice teachers embarking on a study abroad program.

\section{Findings}

The research question that guided this study was how did the study abroad experience affect Spanish teachers' feelings of self-efficacy as it relates to language proficiency and instructional practice? In the following section, we present our findings, based upon the primary data source of 
interviews, which reveal how the study abroad experience enabled the participants to better understand their Spanish-language skills and acknowledge important components of their classroom practice that they would like to change in the future. The pre-trip interview protocol (Appendix A), along with subsequent interview questions, was designed using both the general (non-subject specific) teacher self-efficacy literature (Tschannen-Moran \& Woolfolk Hoy, 2001) as well as research that specifically addresses the self-efficacy of foreign language teachers (Chacón, 2005; Mills \& Allen, 2008; Swanson, 2008, 2010, 2012, 2014; Yilmaz, 2011). Therefore, we present the findings from our primary data source, the pre-trip, in-country and post-trip interviews to better understand how the study abroad experience affects inservice Spanish teachers' feelings of self-efficacy.

\section{Pre-Trip Interviews}

Language proficiency. Given the connection between foreign language teachers' feelings of self-efficacy and their language proficiency (Chacón, 2005; Yilmaz, 2011), participants were asked to self-assess their abilities to read, write, listen and speak in Spanish prior to the start of their study abroad experience. As a native Spanish-speaker, the third author was able to assess the participants' proficiency through conversations and observations she conducted while in Costa Rica, which enabled us to more accurately analyze any discrepancies between the participants' espoused and actual language skills.

While all of the participants described feeling functionally competent in the areas of reading, writing, listening and speaking, they still illustrated differences. Pamela and Alissa expressed the most confidence in their proficiency, indicating that they were comfortable using and/or interpreting the language in virtually all categories or domains. However, the less experienced teachers, Jessica and Katie, said their confidence was contingent upon certain factors. For example, although Jessica felt "generally" confident in her language skills, she did acknowledge that she becomes more uncomfortable when she has to use Spanish in technical domains or while switching tenses. Her overall assessment indicated that she felt weaker with her listening skills and most confident in her reading and writing. Similarly, Katie also shared that she was "fairly confident" in her overall Spanish abilities, being most confident in reading, writing and listening. However, when asked about her oral proficiency, she said that she struggled "when the conversation goes between different tenses."

Instructional Planning. In addition to asking participants to self-assess their language skills, we were also interested in how their confidence and knowledge of their language proficiency affected their instructional planning and subsequent delivery. In other words, did their awareness of their language strengths and/or weakness enhance or hinder the instruction they provided their students? Alissa indicated that she is confident in her abilities to "effectively plan for all levels of instruction" and feels as though her proficiency has a positive impact on her class. Likewise, Pamela said that she's more concerned about the level of her students and whether or not they can handle the linguistic demands of her class. In the rare instances that she is not sure about something, she said she reviews a Spanish grammar manual and is able to move on. Jessica also said that she does not feel as though her proficiency level hinders her instruction and, like Pamela, said that if she has to teach a topic with which she is unfamiliar or less confident, she reviews the material beforehand. However, she did acknowledge that since she had only taught lower levels, her proficiency could affect her instruction in more advanced Spanish courses. Unlike the others, Katie said that her 
proficiency does affect what she can teach and that she "definitely has to take into consideration" her level of proficiency when planning her instructional activities.

Teacher self-efficacy. In addition to asking participants to self-assess their language abilities and its effect on their instructional practice prior to their study abroad experience, they were also asked the following (Appendix A, question 12): "Self-efficacy can be defined as judgment about one's abilities to bring about desired outcomes in student engagement and learning. How would you describe your sense of self-efficacy as a teacher? Once again, we found differences among the experienced and less-experiences teachers.

Pamela and Alissa felt very confident in their abilities to affect student engagement and learning. Pamela shared that her "self-efficacy is high", based upon her students' positive comments about her teaching and their overall successful performance in her classes (i.e. student achievement). Alissa, an experienced educator who has taught all levels of Spanish, also responded by saying she is confident that she can "create a very student-centered environment where they're [the students] engaged and using the language."

Although Jessica and Katie expressed a general belief in their ability to affect student achievement and engagement, it wasn't without limitations. For example, Jessica said she is confident in obtaining the goals and objectives established by her department and district-especially related to teaching grammar-based concepts. However, knowing that she would teach AP Spanish in the upcoming school year, she was "very insecure about moving toward a more communicative approach and relying less on grammar and direct instruction." Katie also expressed a similar sentiment as she felt confident in her teaching abilities but acknowledged that, because she only teaches beginning-level Spanish, she needs to give her students more freedom and not be so scripted.

To further investigate the participants' feelings of self-efficacy as Spanish teachers, we asked them the following (Appendix A, Question 15): What are some factors that, based on your experience, have affected (positively or negatively) your sense of self-efficacy as a foreign language teacher?

Pamela, the most experienced educator within our study, said that having one of her former students want to become a Spanish teacher positively affected her self-efficacy as a teacher because "You feel like you have accomplished something when you get them [the students] that excited about languages." Alissa, another experienced educator, expressed both positive and negative factors by saying that "My knowledge of culture, or lack thereof, reinforces my self-efficacy but also makes me realize that there's more to learn and that it's hard to teach my students about Spanishspeaking countries I've never visited."

Katie felt that living abroad and having to accomplish tasks such as finding an apartment on her own contributed to her feeling more confident in her language abilities, which, in turn, gives her more confidence while teaching. Nonetheless, one of her reasons for studying abroad was to build more confidence in her teaching abilities and to "hopefully be able to teach higher levels...instead of using the scripted materials."

Finally, Jessica said that a positive factor which contributes to her feelings of self-efficacy is that her students are great to work with and seem interested in her teaching and classroom environment. 
However, she also shared a non-instructional experience that had a negative effect on her confidence as a Spanish teacher which involved a native-Spanish speaking custodian in her school who would try to speak to her in Spanish. However, after a short time in which Jessica felt as though she could not effectively communicate with him, she admitted that "He finally stopped talking to me in Spanish, which was embarrassing."

While the pre-trip interviews revealed that, overall, the four participants were at least somewhat comfortable with their language proficiency as well as their self-efficacy as teachers, there were some variations, most of which were clearly delineated by experience. Pamela and Alissa, who had been teaching longer, had a higher self-assessment of their language proficiency as well as their selfefficacy, while the less-experienced teachers (Jessica and Katie) acknowledged both linguistic and instructional deficiencies.

\section{Study Abroad Interviews}

To better determine how the study abroad experience affects Spanish teachers' feelings of selfefficacy as it relates to language proficiency and instructional practice, we conducted at least one incountry, semi-structured interview with each of the four participants. These interviews were approximately 30 minutes and were conducted in-country with the participants by the first and third authors. In these interviews, we asked the participants to assess their language proficiency, both in comparison to their pre-trip self-assessment and also within the context of how they were applying the language while abroad. Furthermore, we asked participants to reflect upon their self-efficacy as foreign language teachers, the extent to which it might have changed since going abroad and how it might affect their instructional practice. In the following sections, we will present the findings from each of the participants' in-country interviews.

Jessica. Although she was confident in her language skills prior to going abroad, Jessica acknowledged that the first few days were difficult, forcing her to confront some language deficits. For example, when asked about her first day at the school, Jessica shared the following:

"I felt comfortable in the house [home stay] but then I went to the school to do my language placement test and the lady looked at me and said 'This is interesting, you speak with fluency but there are some mistakes that we need to fix' That made me feel worse!”.

As researchers, we were also able to confirm Jessica's frustration during her in-country interview as she spoke about her initial experiences interacting in Spanish. However, as she spent more time in the country and interacted with her host family and teachers, she gained confidence in her language skills and her abilities to effectively use Spanish in the classroom to affect student achievement. One strategy that emerged was that she was going to have to better prepare her $A P$ lessons in advance to make sure that her language was adequate to provide the students with the necessary input in the target language. "What I'm going to have to do is literally go through the lesson for the day, because I don't do this in my other classes, but put down notes. Just to double check that I'm saying things correctly." This would also enable her to remain in the target language a significant portion of the class, which she acknowledged was important. Jessica also collected authentic materials that she could use in her classrooms, thus giving her more confidence in her ability to provide her students with more authentic, content-based instruction. She wanted to use some of the activities she observed in her Costa Rican classes (3 - 4 students) with her own students 
but was concerned about the practical implementation, given her large class sizes. Furthermore, she was able to develop cultural lessons based on some of the excursions she took while in Costa Rica. For example, while on a tour of a coffee farm, she thought it would be interesting to create a related unit for her students to provide a context in which to use the target language and learn about Costa Rican coffee. "I thought it would be a really fun unit for my kids. We can talk about coffee in the United States and other parts of the world."

Katie. As one of the younger and least-experienced Spanish teachers in the study, Katie's pretrip comments revealed that although she felt "fairly comfortable" with her Spanish skills and related instructional aptitude, she was still aware of deficiencies. This pre-trip awareness of her language deficiencies was reinforced during our in-country interviews when she admitted "I know that I still struggle with some of the hypothetical phrases, but I'm doing fine with day-to-day communication". As in-country researchers, we also observed that Katie was somewhat apprehensive at first to use the language in authentic interactions. This was further supported by one of her journal entries that revealed an awareness of language errors along with a compensation strategy: "I am very aware of the errors I am making so I'm trying to speak slowly and pay close attention to them [the errors]".

Katie also identified that the study abroad experience was valuable to her own instructional practices. For example, when asked to self-assess her sense of self-efficacy as a foreign language teacher before going abroad, Katie said "I think I do a good job scaffolding my teaching so students know what's expected of them and they can produce [Spanish] confidently; I still struggle to use Spanish more often". However, after spending time abroad where she was exposed to classes conducted entirely in Spanish, Katie wrote in her journal that "I know in the classroom that I will be able to stay in the target language much longer than in the past". The experience also gave her the opportunity to incorporate ideas and strategies that she witnessed as a learner into her own classroom as she said that "I'm always asking myself [while in class] 'How could I use this?". However, like Jessica, she was unsure of the practicality of using these activities with her students due to her class sizes, which regularly had 20 or more students.

Pamela. Despite her pre-trip beliefs that her language proficiency was advanced, after a short time abroad, Pamela admitted that she needed more practice in all areas of Spanish and, as a result, her stress level was "a little high". In one of her first in-country journal entries Pamela wrote "My first couple of days I felt overwhelmed...I intend to study more [Spanish] on my own when I get home!" When asked what steps she could take to improve her language skills, Pamela's response reflected a very traditional, grammar-based philosophy as she simply wanted to learn more vocabulary and review verb tenses. She commented that "My language ability is probably a little lower than I thought. Or maybe it's because I jumped into some tenses that I'm not comfortable with." When first asked if the experience had already caused her to make changes to her own instruction she stated "I just feel like the format I'm using is going to work for me." However, as she spent more time abroad, not only did she become more comfortable using Spanish, but she acknowledged that she had re-assessed her instructional effectiveness and realized the need to infuse her lessons with more authentic culture. To accomplish this, she started taking more pictures and buying various forms of realia to bring home and use with her students. Furthermore, she committed to using the target language more, saying "It will be more work [using the TL], but it will be worth if it they [students] start hearing more and understanding more." When asked to reflect 
upon any changes in her self-efficacy as a teacher, her in-country responses indicated that she felt the same as before but was more focused on improving her language skills. Overall, as in-country researchers, we observed the widest range of emotions and growth from Pamela.

Alissa. Throughout the study we observed that Alissa was very comfortable using the target language both in and outside of her Costa Rican classes. As a veteran teacher with more than a decade of experience, prior to going abroad she was confident in her language and instructional abilities. Nonetheless, she was very eager to modify her instructional practice, based upon her experiences in Costa Rica. Unlike the other participants who, when asked to self-assess any deficiencies in their oral proficiency, focused primarily on grammar, Alissa recognized a more global approach and mentioned that while she didn't recognize any significant or specific language deficiencies, she still needed more exposure and practice because, in her words "your proficiency impacts the class". Similar to the other participants, she also valued her experiences as a student and wanted to incorporate the small-group activities she witnessed abroad into her own classes. However, unlike the other participants, she was not discouraged by her large class sizes, which routinely exceeded 30 students. She was also committed to providing more comprehensible input and staying in the target language "at least $90 \%$ of the time." Finally, she realized the importance of teaching content using Spanish and while still in Costa Rica, emailed a colleague in the science department at her high school to explore possibilities of cross-curricular planning. When asked how the experience was contributing to her self-efficacy as a teacher, Alissa said that it had given her a "renewed sense of excitement to return to the classroom" and she was convinced that "our efficacy and our confidence completely depends on where we're at with our spoken Spanish."

The in-country interviews and subsequent observations that we made of the participants while studying abroad were very revealing as we were able to see growth in all of the participants in terms of their language proficiency and overall feelings of self-efficacy, which supported the purpose of this study. Furthermore, participants' in-country comments to our interview questions demonstrated an awareness of the fluidity of their language proficiency and instructional practice.

\section{Post-Trip Interviews}

We conducted a final, post-trip interview with the participants within two weeks of returning back to the United States. This was a very important step and data point as it provided us with the participants' thoughts and final reactions, after having some time to readjust to their home life and reflect upon the study abroad experience. Similar to the pre-trip interviews, all post-trip interviews were conducted online due to geographical constraints. Using a semi-structured interview format, we further explored the research question to determine how the study abroad experience affected the participants' feelings of self-efficacy as it relates to language proficiency and instructional practice.

Jessica. As a result of studying abroad, Jessica recognized the impact it had on her language proficiency, primarily because it made her aware of her deficiencies and caused her to articulate ways to address those needs. For example, an unintended linguistic benefit of the experience is that she became aware of her Spanish-speaking accent and made an effort to improve it, since she realized that it affected her students' language development and achievement. Furthermore, studying abroad caused her to reflect upon her own instructional practices as she recognized areas in need of 
modification and/or improvement. As previously stated, she enjoyed the size of her classes in Costa Rica (3 - 4 students) because it allowed for more authentic interaction and target language use. However, she felt somewhat discouraged because she was unsure if she could replicate that in her own classes, which usually had a least 20 students. She said "I'm sitting here trying to figure it out, how do I bring this really good teaching experience to my students and still not have massive chaos?" Nonetheless, she admitted that there was no excuse to not use the target language more often in her classroom saying "I need to get over it and just do it." Furthermore she thought the study abroad experience affected her self-efficacy as a teacher-especially as she prepared to teach AP Spanish for the first time-by making her more aware of her abilities, deficiencies and, most importantly, realizing that she is able to take steps improve.

Katie. Based on her interviews, reflections and our personal observations, Katie demonstrated the most need for growth in terms of her self-efficacy related to language proficiency and instructional practice. When asked to reflect upon her time studying abroad and self-assess any improvements in her language skills, she said "I feel like my proficiency increased. I feel more confident than before". In addition, she felt as though the study abroad experience made her excited to return to the classroom and to remain in the teaching profession: "It [studying abroad] gave me a little bit more of a push. I'm excited to keep teaching."

Katie also acknowledged the benefit the study abroad experience had on improving her instructional practice through observing strategies used by her Costa Rican instructors as well as learning from other foreign language teachers who were studying at the same school. When asked to comment on learning from her teachers and colleagues she said "We talked about different exercises to get students to talk and how to use those open-ended questions such as pair-shares. Seeing as a student and then discussing it with other teachers reinforces what works and what doesn't'. Finally, studying abroad gave Katie added confidence to be a better teacher and made her realize that she needed to provide her students with more authentic input. As a result, she made a commitment to "stay in the target language $90 \%$ of the time" while teaching her classes the upcoming school year.

Pamela. Despite her pre-trip assertions related to both her language proficiency and instructional practice, the study abroad experience was very transformative for Pamela. She indicated the she "enjoyed the entire experience", especially attending classes and generating ideas for her own instruction. When asked about the effect that studying abroad had on her self-efficacy as a Spanish teacher, she said "I think my self-efficacy is about the same. I kind of went up and down the ladder while I was there. When I was frustrated, I felt like I wasn't very effective." She also showed growth in her willingness to change her pedagogy, albeit in small increments:

"I have really great ideas on how I'm going to change what I'm doing in the classroom. Not overnight... but I have ideas for what to do with the pictures I took. I can see a lot of improvement coming over the next couple of years."

In addition, Pamela still felt very comfortable with her overall language proficiency but admitted in her final journal entry that the study abroad experience caused her to realize that she "still has some things to learn and can always improve". 
Alissa. Interestingly, while both Alissa's self-assessment of her language skills and self-efficacy indicated that she was very proficient in both areas, her comments revealed that she might have gained the most from her time abroad. She thought it was a "great experience" and that her selfefficacy as a Spanish teacher improved, along with her language skills and overall eagerness to return to the classroom. Although all of the participants recognized the value of being foreign language students, it appeared to be more meaningful to Alissa as she commented that, from a student's perspective "I think sometimes I forget that it doesn't matter how relaxing or comfortable the classroom is, it's still hard to use the second language." Furthermore, it reinforced her goal to use the target language more in the class and to implement more meaningful activities designed to promote communication and acquisition: "I'm ready. I'm pumped to go back and be at almost 100\% target language use." As a result of the cultural benefits of studying abroad, Alissa said "I'm excited to give my students new phrases and slang and so many cool cultural things I learned about the country". When asked how her classroom might be different because of studying abroad, she said "I think you'll see more meaningful exchanges and conversation that are spontaneous rather than structured".

\section{Discussion}

The purpose of this qualitative inquiry was to add to the limited research about how the study abroad experience contributes to inservice foreign language teachers' feelings of self-efficacy, especially as it relates to language proficiency and instructional practice. While previous research has focused on the self-efficacy of foreign language teachers (Chacón, 2005; Mills \& Allen, 2008; Swanson, 2008, 2010, 2012, 2014; Yilmaz, 2011), the present study represents a unique contribution to the literature as it analyzes the lived experiences of inservice Spanish teachers studying abroad and how their interpretation of those experiences contributes to the development of their linguistic and pedagogical skills. Consequentially, the following themes emerged from this study: (a) after spending time in the target culture, all participants realized deficiencies in their languages skills (b) all participants developed a better understanding of their own students as a result of being a foreign language learner and (c) all participants were committed to using the target language (Spanish) in their classrooms at least $90 \%$ of the time. Clearly, spending time in the target culture, with the additional, structured support of studying abroad, enabled these inservice teachers to identify both strengths and weaknesses in their professional practice that would not have otherwise been accessible. Of primary importance is the impact that studying abroad had on their understanding of their language proficiency and the various attributes associated with positively affecting student achievement and engagement in their classrooms, thus indicating a higher level of self-efficacy. Additionally, their commitment to use Spanish more in their classroom, at least $90 \%$ of the time, was very profound since $90 \%$ target language (TL) use reflects best practice in foreign pedagogy as evidenced by the American Council on the Teaching of Foreign Languages Position Statement on Use of the Target Language in the Classroom (2010). According to LeLoup, Ponterio and Warford (2013), teachers at all levels of foreign language not only struggle to meet this $90 \%$ but "many teachers appear to be perpetuating a system wherein much instruction takes place in the L1 and, indeed, the TL at times takes on a secondary role" (p. 52). Studying abroad was a significant experience for these educators because it served as an impetus for both personal and professional growth.

There also needs to be a heightened awareness among prominent stakeholders (such as school administrators) of the need for continued study abroad among current inservice teachers as a form 
of professional development. Jochum, Rawlings and Tejada (2015) examined the experiences of Spanish teachers studying abroad and found it to be a unique and necessary form of professional development, since "the traditional model of inservice professional development for all teachersthe workshop-may fail to address the complex needs of foreign language teachers" (p. 130). Underscoring this need are the time and financial resources required to spend adequate time abroad. This can be especially challenging for inservice foreign language teachers who often times have additional professional responsibilities during the summer months, which is the best time to travel. Therefore, both inservice teachers and administrators should pursue sources of funding both within their respective school districts and externally, through professional organizations that support study abroad. School administrators should also consider offering professional development credit for these experiences, which are often times necessary for licensure recertification. Additionally, colleges and universities should explore programmatic opportunities that would enable them to not only organize study abroad trips for inservice teachers, but to also provide graduate-level credit.

Spending time abroad provides teachers unique access to the products, perspectives and practices of the target culture as well as frequent opportunities to use their language skills in realworld scenarios. Previous research has supported the notion of language maintenance among foreign language teachers through authentic, language-based activities and spending more time abroad (Cooper, 2004; Fraga-Cañadas, 2010). It is estimated that language learners need at least 720 hours of formal instruction in the foreign language to reach advanced levels on the ACTFL Proficiency Guidelines (Liskin-Gasparro, 1982; Malone, Rifkin, Christian, \& Johnson, 2005). A typical undergraduate program which consists of 30-36 credit hours of foreign language courses equates to only 450 to 540 hours. Therefore, foreign language teachers who hope to progress beyond minimally-required levels of language proficiency must spend time in the foreign or target culture, preferably taking part in a study abroad program.

\section{Limitations and Future Research}

While the results of this study provide a unique contribution to the field of foreign language education through analyzing how the study abroad experience contributed to inservice Spanish teachers' self-efficacy, the findings still present limitations. Although case studies provide an in-depth understanding of participants' lived experiences, they are still limited to the confines of the respective cases or subjects. One of the primary limitations in this study is that the participants shared common interests and backgrounds as graduate students who decided to study abroad to enhance their language and teaching skills. Therefore, they were not randomly selected for the study. Furthermore, while the findings of this study report improvements in self-efficacy and language proficiency, it is important to note that these measures were based on self-reported data, and not standardized assessment instruments.

Despite the aforementioned limitations, this study does provide new information about the many variables affecting the self-efficacy of foreign language teachers and how studying abroad can enhance teachers' professional practice, language proficiency and, most importantly, student achievement. It has also shown the importance of studying abroad on inservice teachers' ability to reflect on their instruction, which, in this study, also resulted in a commitment to reach the goal of teaching in the target language at least $90 \%$ of the time. 
Future research in this field should continue to investigate the benefits of studying abroad on inservice foreign language teachers' language development, self-efficacy and commitment to achieving and/or maintaining 90\% target-language use in the classroom. Additionally, because this study focused on the experiences of Spanish teachers, it would be illuminating to conduct similar inquires involving teachers of other foreign languages such as French and German. Finally, since the results of this study were based on self-reported and/or observed data, future researchers would be well-advised to employ a mixed-design to build upon the results of this study and to better quantify gains in self-efficacy and proficiency through survey instruments and standardized language assessments.

Studying abroad is a necessary part of professional development for foreign language teachers who want to be able to positively affect student engagement and achievement in their classrooms. In her post-trip interview, Alissa clearly articulated this with the following: "I can't even believe that there are Spanish teachers who never studied abroad. I think we are doing a huge disservice to foreign language education if, as teachers, we're not going abroad every few years."

\section{References}

Allen, H. W., \& Herron, C. A. (2003). A mixed methodology investigation of the linguistic and affective outcomes of summer study abroad. Foreign Language Annals, 36(3), 370-384.

Allen, H. W. (2010). Language-learning motivation during short-term study abroad: An Activity theory perspective. Foreign Language Annals, 43(1), 27-49.

Allinder, R. M. (1994). The relationship between efficacy and the instructional practices of special education teachers and consultants. Teacher Education and Special Education, 17, 86-95.

American Council on the Teaching of Foreign Languages. (2010). Position statement on use of the target language in the classroom. Retrieved from http://www.actfl.org/news/position-statements/use-thetarget-language-the-classroom- 0 .

American Council on the Teaching of Foreign Languages. (2012). ACTFL proficiency guidelines [Electronic version]. $\quad$ Retrieved from http://www.actfl.org/sites/default/files/pdfs/public/ACTFLProficiencyGuidelines2012_FINAL.pdf

American Council on the Teaching of Foreign Languages. (2013, August). ACTFL/CAEP program standards for the preparation of foreign language teachers. [Electronic version]. Retrieved from http://www.actfl.org/sites/default/files/pdfs/ACTFL-Standards20Aug2013.pdf

Ashton, P.T., \& Webb, R. B. (1986). Making a difference: Teachers' sense of efficacy and student achievement. New York: Longman.

Bandura, A. (1977). Self-efficacy: Toward a unifying theory of behavioral change. Psychological Review, 84. 191-215.

Bandura, A. (1997). Self-efficacy: The exercise of control. New York: W. H. Freeman.

Brand, B. R., \& Wilkins, J. L. M. (2007). Using self-efficacy as a construct for evaluating science and mathematics methods courses. Journal of Science Teacher Education, 18, 297-317.

Brecht, R. D., Davidson, D. E., \& Ginsberg, R. B. (1995). Predictors of foreign language gain during study abroad. In B. F. Freed (Ed.), Second language acquisition in a study abroad context (pp. 3766). Amsterdam: John Benjamins Publishing.

Burley, W. W., Hall, B. W., Villeme, M. G., \& Brockmeier, L. L. (1991). A path analysis of the mediating role of efficacy in first-year teachers' experiences, reactions and plans. Paper presented at the annual meeting of the American Educational Research Association, Chicago.

Chacón, C. T. (2005). Teachers' perceived efficacy among English as a foreign language teachers in middle schools in Venezuela. Teaching and Teacher Education, 21(3), 257-272.

Collentine, J. (2004). The effects of learning contexts on morphosyntactic and lexical development. Studies in Second Language Acquisition, 26, 227-248. 
Cooper, T. C. (2004). How foreign language teachers in Georgia evaluate their professional preparation: A call for action. Foreign Language Annals, 37(1), 37-48.

Covert, H. H. (2014). Stories of personal agency: Undergraduate students' perceptions of developing intercultural competence during a semester abroad in Chile. Journal of Studies in International Education, 18(2), 162-179.

Cubillos, J. H., \& Ilvento, T. (2012). The impact of study abroad on students' self-efficacy perceptions. Foreign Language Annals, 45(4), 494-511.

Enochs, L. G., \& Riggs, I. M. (1990). Further development of an elementary science teaching efficacy belief instrument: A preservice elementary scale. School Science and Mathematics, 90(8), 695-706.

Fraga-Cañadas, C. P. (2010), Beyond the classroom: Maintaining and improving teachers' language proficiency. Foreign Language Annals, 43(3), 395-421.

Freed, B. F. (1995). What makes us think that students who study abroad become fluent? In B. F. Freed (Ed.), Second language acquisition in a study abroad context (pp. 123-148). Amsterdam: John Benjamins Publishing.

Gibson, S., \& Dembo, M. (1984). Teacher efficacy: A Construct validation. Journal of Educational Psychology, 76(4), 569-582.

Guskey, T. R. (1984). The influence of change in instructional effectiveness upon the affective characteristics of teachers. American Educational Research Journal, 21, 245-259.

Hall, B., Burley, W., Villeme, M., \& Brockmeier, L. (1992). An attempt to explicate teacher efficacy beliefs among first year teachers. Paper presented at the annual meeting of the American Educational Research Association, San Francisco.

Huffaker, D. A., \& Calvert, S. L. (2005). Gender, identity, and language use in teenage blogs. Journal of Computer-Mediated Communication, 10(2). doi:10.1111/j.10836101.2005.tb00238.x.

James, N. \& Busher, H. (2009) Online interviews: Epistemological, methodological and ethical considerations in qualitative research, London: Sage.

Jochum, C. J. (2014). Measuring the effects of a semester abroad on students' oral proficiency gains: A comparison of at-home and study abroad. Frontiers: The Interdisciplinary Journal of Study Abroad, 24, 93-104.

Jochum, C. J., Rawlings, J. R., \& Tejada, A. M. (2015). Study abroad as professional development: Voices of in-service Spanish teachers. In P. Swanson (Ed.) Dimension: 50 years of Language Teaching and Learning (pp. 121-135). Decatur, GA: Southern Conference on Language Teaching.

LeLoup, J. W., Ponterio, R., \& Warford, M. K. (2013). Overcoming resistance to $90 \%$ target language use: Rationale, challenges, and suggestion. NECTFL Review, 72, 45-60.

Liskin-Gasparro, J. E. (1982). ETS Oral Proficiency Testing Manual. Princeton, N. J.: Educational Testing Service.

Malone, M., Rifkin, B., Christian, D., \& Johnson, D. (2005). Attaining high levels of proficiency: Challenges for foreign language education in the United States. CAL Digests.

Medina, A. L., Hathaway, J. I., \& Pilonieta, P. (2015) How preservice teachers'study abroad experiences lead to changes in their perceptions of English language learners. Frontiers: The Interdisciplinary Journal of Study Abroad, 25, 73-91.

Midgley, C., Feldlaufer, H., \& Eccles, J. (1989). Change in teacher efficacy and student self- and taskrelated beliefs in mathematics during the transition to junior high school. Journal of Educational Psychology, 81, 247-258.

Mills, N. A., \& Allen, H. W. (2008). Teacher efficacy in native and non-native teaching assistants of French. In J. Siskin (Ed.), From thought to action: Exploring beliefs and outcomes in the foreign language program (pp. 213-234). Boston: Heinle.

Moore, W., \& Esselman, M. (1992). Teacher efficacy, power, school climate and achievement. A desegregating district's experience. Paper presented at the annual meeting of the American Educational Research Association, San Francisco.

Parkay, F. W., Greenwood, G., Olejnik, S., \& Proller, N. (1988). A study of the relationship among teacher efficacy, locus of control, and stress. Journal of Research and Development in Education, 27(4), 13- 
22.

Patton, M. Q. (2002). Qualitative research \& evaluation methods. (3 ${ }^{\text {rd }}$ ed.). Thousand Oaks: Sage.

Ross, J. A. (1992). Teacher efficacy and the effect of coaching on student achievement. Canadian Journal of Education, 17(1), 51-65.

Salmon, G. (2000). Computer mediated conferencing for management learning at the Open University. Management Learning, 31(4), 491-502.

Schmidt-Rinehart, B. C., Knight, S. M. (2004). The homestay component of study abroad: Three perspectives. Foreign Language Annals 37(2). 254-262.

Segalowitz, N., \& Freed, B. F. (2004). Context, Contact, and Cognition in Oral Fluency Acquisition: Learning Spanish in At Home and Study Abroad Contexts. Studies In Second Language Acquisition, 26(2), 173-199.

Seidman, I. (2012). Interviewing as qualitative research: A guide for researchers in education and the social sciences $\left(4^{\text {th }}\right.$ ed.). New York: Teachers College Press.

Stake, R. E. (2006). Multiple case study analysis (1st ed.). NY: The Guilford Press.

Swanson, P. (2008). Efficacy and interest profile of foreign language teachers during a time of critical shortage. NECTFL Review, 62, 55-74.

Swanson, P. B. (2010). Teacher efficacy and attrition: Helping students at introductory levels of language instruction appears critical. Hispania, 93(2), 305-321.

Swanson, P. (2012). Second/foreign language teacher efficacy and its relationship to professional attrition. Canadian Modern Language Review, 68(1), 78-101.

Swanson, P. (2014). The power of belief: Spanish teachers' sense of efficacy and student performance on the National Spanish Examinations. Hispania 97(1), 5-20.

Swender, E. (2003). Oral proficiency testing in the real world: Answers to frequently asked questions. Foreign Language Annals, 36(4). 520-535.

Tschannen-Moran, M., \& Woolfolk Hoy, A. (2001). Teacher efficacy: Capturing an elusive construct. Teaching and Teacher Education, 17, 783-805.

Tschannen-Moran, M., \& Johnson, D. (2011). Exploring literacy teachers'self-efficacy beliefs: Potential sources at play. Teaching and Teacher Education, 27, 751-761.

Yilmaz, C. (2011). Teachers' perceptions of self-efficacy, English proficiency and instructional strategies. Social Behavior \& Personality: An International Journal, 39(1), 91-100. 
Appendix: Interview Protocol

1. What is your name?

2. How old are you?

3. How do you describe your race or ethnicity?

4. How many years have you been teaching Spanish?

5. What is your highest earned degree?

6. Do you have previous study abroad experience(s)? If so, please explain.

7. What is your current teaching assignment? What levels of Spanish do you teach?

8. What size of school do you teach in?

9. Describe the level of administrative support you feel for your job and foreign language education.

10. Describe the level of parental support you feel for your job and foreign language education.

11. Self-assess your Spanish abilities in reading, writing, listening and speaking.

12. Self-efficacy can be defined as judgment about one's abilities to bring about desired outcomes in student engagement and learning. How would you describe your sense of self-efficacy as a teacher?

13. How comfortable are you / would you be teaching upper level Spanish? What about native or heritage speakers?

14. When you're planning lessons and activities, do you ever take into account your own level of proficiency?

15. What are some factors that, based on your experience, have affected (positively or negatively) your sense of self-efficacy as a foreign language teacher?

16. Current statistics show that a large number of teachers-up to 50\%-will leave the profession within their first three to five years. How do you perceive your longevity in the profession and what are some contributing factors?

17. What are some of your professional goals?

18. What do you do to keep up your Spanish proficiency? What could you do more of? 